\title{
Sinais Ultra-sonográficos em Fetos Portadores de Toxoplasmose Congênita
}

\author{
Ultrasonographic Markers for Fetal Congenital Toxoplasmosis
}

Júlio César de Faria Couto, Juliana Moysés Leite

\section{RESUMO}

\begin{abstract}
Objetivo: descrever as alterações ultra-sonográficas em fetos com toxoplasmose congênita, correlacionando-as com o prognóstico neonatal.

Métodos: entre junho de 1997 e maio de 2003 foram examinadas 150 gestantes com suspeita de toxoplasmose. A infecção aguda foi confirmada em 72 (48\%) gestantes e a toxoplasmose congênita foi diagnosticada em 12 (16\%) fetos. O diagnóstico pré-natal foi realizado pela reação em cadeia da polimerase no liquido amniótico. Todas as pacientes receberam terapia antiparasitária. O acompanhamento ultra-sonográfico foi quinzenal e todos os recém-nascidos foram acompanhados no primeiro ano de vida.

Resultados: as alterações ultra-sonográficas foram observadas em oito fetos. Todos apresentavam dilatação ventricular bilateral, associada a calcificações periventriculares em cinco casos. Outras alterações como calcificação hepática, hepatomegalia, poliidrâmnio $e$ derrame pericárdico foram menos freqüentes. Dentre esses fetos, quatro foram neomortos $e$ três apresentaram seqüelas (coriorretinite e retardo neuropsicomotor). Os quatro fetos com ultra-sonografia normal evoluiram satisfatoriamente.

Conclusão: observou-se elevada incidência de alterações ultra-sonográficas nos fetos com toxoplasmose congênita, principalmente cerebrais. Outras alterações como hepatomegalia e derrame pericárdio são menos freqüentes e traduzem infecção sistêmica. O prognóstico dos fetos parece correlacionar-se com a presença de lesões ultra-sonográficas, uma vez que nesse grupo de fetos observou-se alta mortalidade e entre os sobreviventes a incidência de seqüelas foi importante. Os fetos sem alterações ultra-sonográficas evoluiram de forma favorável, sem seqüelas de desenvolvimento. Esses resultados destacam a importância da ultra-sonografia no acompanhamento desses fetos, a fim de se estabelecer um prognóstico e permitir a elaboração de conduta pós-natal adequada.
\end{abstract}

PALAVRAS-CHAVE: Toxoplasmose congênita. Ultra-sonografia. Diagnóstico pré-natal.

\section{Introdução}

A infecção pelo Toxoplasma gondii é altamente prevalente e freqüentemente assintomática. O feto, no entanto, pode ser gravemente acometido como resultado de infecção materna durante a gestação ${ }^{1}$. No Brasil, entre 25 e $40 \%$ das gestantes são soronegativas para a toxoplamose ${ }^{2,3}$. O risco de infecção aguda durante a gestação é de aproximadamen-

Ambulatório de Toxoplasmose e Gestação - Santa Casa de Belo Horizonte - MG

Correspondência:

Júlio César Faria Couto

Rua Nelson Soares de Faria, 366/101 - Cidade Nova

31170-030 - Belo Horizonte - MG

Telefone: (31) 8853-1517 Fax: (31) 3484-2297

e-mail: juliocouto2001@yahoo.com.br te $1 \%$ e a transmissão fetal ocorre em $30 \%$ dos casos, levando a infecção fetal de gravidade variável ${ }^{1,4}$.

A utilização da biologia molecular revolucionou o acompanhamento pré-natal da toxoplasmose, pois, além de permitir a identificação dos fetos infectados, possibilitou que a terapia antiparasitária fosse iniciada precocemente, ainda na gestação ${ }^{5-9}$. O diagnóstico pré-natal da toxoplasmose congênita apresenta importantes implicações para o prognóstico fetal, assim como para a evolução neonatal, possibilitando o acompanhamento por uma equipe multidisciplinar, com identificação precoce de alterações durante a gestação, parto e no periodo pósnatal imediato, permitindo que os cuidados do recém-nascido sejam otimizados a fim de melhorar o prognóstico dessas crianças. No entanto, embora altamente sensiveis para o diagnóstico pré-natal 
da toxoplasmose congênita, os exames de biologia molecular não permitem a avaliação do prognóstico fetal.

O aperfeiçoamento dos aparelhos de ultrasonografia e a melhor capacitação médica têm permitido o conhecimento da história natural das doenças fetais. O acompanhamento ultra-sonográfico dos fetos portadores de infecções congênitas possibilitou a compreensão tanto de sua evolução antenatal quanto de sua fisiopatologia. A ultrasonografia tem importância fundamental no acompanhamento e na avaliação do prognóstico dos fetos portadores de toxoplasmose, pois permite identificar aqueles sem sinais de infecção congênita (assintomáticos), cujo prognóstico normalmente é favorável, e os fetos apresentando alterações ultrasonográficas compativeis com toxoplasmose congênita, cujo prognóstico depende fundamentalmente das lesões encontradas e da evolução das mesmas.

As alterações ultra-sonográficas observadas nesses fetos têm recebido grande atenção da literatura especializada ${ }^{4,5,7,8}$. A incidência de anomalias ultra-sonográficas varia de $18,1 \%{ }^{5,6}$ a $36,4 \%{ }^{7}$, estando associada à idade gestacional da infecção fetal ${ }^{5}$. As alterações observadas com maior freqüência são dilatação ventricular e calcificações intracranianas ${ }^{8}$. Já as anomalias extracerebrais, compativeis com infecção fetal sistêmica, são encontradas em $65 \%$ dos casos quando a infecção fetal ocorre no primeiro trimestre e em $25 \%$ dos casos quando ocorre no segundo trimestre da gestação ${ }^{8}$. Entretanto, pouco destaque tem sido dado à correlação entre essas alterações ultra-sonográficas observadas no pré-natal e a evolução desses recém-nascidos.

Dessa forma, o objetivo deste trabalho foi descrever as alterações ultra-sonográficas observadas em grupo de fetos portadores de toxoplasmose congênita, correlacionando-as com o prognóstico neonatal.

\section{Pacientes e Métodos}

Foram incluídas inicialmente 150 gestantes encaminhadas ao Ambulatório de Toxoplasmose e Gestação da Santa Casa de Belo Horizonte no período de junho de 1997 a maio de 2003 com suspeita de toxoplasmose aguda na gestação após rastreamento sorológico de rotina.

Os critérios utilizados para confirmação de infecção aguda foram: soroconversão (detecção de anticorpos específicos IgM ou IgG em pacientes suscetíveis cuja última amostra obtida na gestação era negativa), variação na concentração dos anticorpos IgM e/ou IgG entre dois exames reali- zados com intervalo de três semanas e presença de anticorpos IgM associados a anticorpos IgA. Todos os exames foram realizados pela técnica ELFA (enzyme linked fluorescent assay), método imunoensaio enzimático do tipo sanduíche com detecção final em fluorescência (Kit Vidas Toxo IgG II, IgM e IgA, BioMérieux, Lyon, França).

Para o diagnóstico da infecção fetal utilizouse a reação em cadeia da polimerase (PCR) em amostras de líquido amniótico colhidas por amniocentese após a $18^{\mathrm{a}}$ semana de gestação, realizada com intervalo mínimo de quatro semanas após a infecção materna. Foi realizada a amplificação de uma mesma seqüência alvo de repetição do gen B1 do T. gondii. Em todas as reações, a sensibilidade da PCR foi monitorada utilizando DNA controle. Os exames foram realizados no Núcleo de Apoio e Desenvolvimento à Pesquisa (NUPAD) da Universidade Federal de Minas Gerias (UFMG).

Todas as pacientes receberam espiramicina ( $3 \mathrm{~g} /$ dia), pirimetamina (50 $\mathrm{mg} / \mathrm{dia})$, sulfadiazina ( $3 \mathrm{~g} /$ dia) e ácido folínico (30 mg/semana), conforme o resultado da PCR.

O acompanhamento ultra-sonográfico foi realizado por um único observador com intervalo quinzenal. Foram utilizados os aparelhos Aloka modelo SSD 650 (3,5 MHz) (Aloka Ltd., Tóquio, Japão) e Siemens Sonoline Versa Plus $(3,5 \mathrm{MHz})$ (Siemens Medical Systems, Inc., Alemanha). Os marcadores ultra-sonográficos utilizados neste estudo foram: dilatação ventricular (medida do átrio do ventrículo lateral maior ou igual a $10 \mathrm{~mm}$ ), calcificações intracranianas (imagens hiperecogênicas, nodulares, grosseiras e sem sombra acústica posterior, únicas ou múltiplas, de localização periventricular ou intraparenquimatosa), espessamento placentário (medida da maior espessura placentária maior ou igual ao percentil 90 para a idade gestacional) ${ }^{9}$, hepato-esplenomegalia (comprimento do figado e baço maior ou igual ao percentil 90 para a idade gestacional), derrame pericárdico (presença de líquido na cavidade pericárdica contíguo a mais de uma câmara cardiaca), crescimento intra-uterino restrito (CIUR), peso fetal estimado menor que o percentil 10 para a idade gestacional segundo a curva de Hadlock et. $\mathrm{al}^{9}$, poliidrâmnio (índice de líquido amniótico (ILA) maior que o percentil 90 para a idade gestacional) e calcificação hepática (imagem hiperecogênica, nodular, sem sombra acústica posterior e normalmente única).

Todos os recém-nascidos foram submetidos a exame clínico e propedêutica específica: radiografia de crânio, fundo de olho, dosagem de anticorpos IgM e IgG, punção lombar e eventualmente ultra-sonografia transfontanela. Todas as 
crianças foram encaminhadas ao Centro de Tratamento e Referência para Doenças Infecto-Parasitárias (CTR-DIP) do Hospital das Clínicas da UFMG e ao ambulatório de pediatria da Santa Casa de Belo Horizonte para acompanhamento.

O diagnóstico definitivo da infecção foi realizado no período pós-natal por meio de acompanhamento clínico e sorológico. A infecção congênita foi confirmada pela persistência dos anticorpos IgG nos primeiros 12 meses de vida, pela detecção de anticorpos IgM específicos ou pelo aparecimento de sinais e sintomas clínicos relacionados à toxoplasmose. Os recém-nascidos foram considerados não infectados quando houve diminuição progressiva dos anticorpos IgG até a sua negativação.

O estudo foi aprovado pelo Comitê de Ética em Pesquisa (CEP) da Santa Casa de Belo Horizonte.

\section{Resultados}

A infecção aguda foi confirmada em 72 gestantes $(48 \%)$ e a toxoplasmose congênita foi diagnosticada em 12/72 (16\%) fetos. Em cinco casos a infecção ocorreu no primeiro trimestre, três gestantes foram contaminadas no segundo trimestre e em quatro casos não foi possivel determinar a idade gestacional na qual ocorreu a infecção materna (Tabela 1).
Tabela 1 - Número de fetos apresentando alterações ultra-sonográficas conforme a idade gestacional em que ocorreu a infecção fetal.

\begin{tabular}{lcc}
\hline $\begin{array}{l}\text { Idade gestacional } \\
\text { da infecção fetal }\end{array}$ & $\begin{array}{c}\text { Número de fetos } \\
\text { examinados }\end{array}$ & $\begin{array}{c}\text { Número de fetos com } \\
\text { alterações ultra-sonográficas }\end{array}$ \\
\hline $1^{0}$ trimestre & 5 & 3 \\
$2^{0}$ trimestre & 3 & 2 \\
Indeterminado & 4 & 3 \\
Total & 12 & 8 \\
\hline
\end{tabular}

Tabela 2 - Alterações ultra-sonográficas encontradas nos oito fetos sintomáticos

\begin{tabular}{lc}
\hline Alterações ultra-sonográficas & $\mathbf{n}$ \\
\hline Lesões cerebrais & $8 / 8$ \\
Dilatação ventricular & 8 \\
Calcificação intracraniana & 5 \\
Alterações Placentárias & $3 / 8$ \\
Espessamento placentário & 3 \\
Alterações hepáticas & $3 / 8$ \\
Calcificação hepática & 1 \\
Hepatomegalia & 2 \\
Outras alterações & $5 / 8$ \\
Poliidrâmnio & 2 \\
Derrame pericárdico & 1 \\
Esplenomegalia & 1 \\
ClUR & 1 \\
\hline
\end{tabular}

CIUR: crescimento intra-uterino restrito.

Tabela 3 - Alteração ultra-sonográfica no pré-natal e evolução clínica pós-natal nos fetos infectados.

\begin{tabular}{|c|c|c|c|c|c|c|}
\hline $\begin{array}{c}\text { Caso } \\
n^{0}\end{array}$ & $\begin{array}{c}\text { Alterações } \\
\text { ultra-sonográficas }\end{array}$ & $\begin{array}{l}\text { IG da infecção } \\
\text { materna }\end{array}$ & $\begin{array}{l}\text { Tratamento } \\
\text { materno }\end{array}$ & $\begin{array}{l}\text { IG do parto } \\
\text { (semanas) }\end{array}$ & $\begin{array}{c}\text { Peso } \\
\text { (gramas) }\end{array}$ & Evolução clínica pós-natal \\
\hline 1 & $\begin{array}{l}\text { Dilatação ventricular, calcificação } \\
\text { intracraniana, hepatomegalia, } \\
\text { espessamento placentário, } \\
\text { poliidrâmnio }\end{array}$ & $2^{0}$ trimestre & Regular & 37 & 2.480 & $\begin{array}{l}\text { Corioretinite bilateral. Progressão } \\
\text { da dilatação ventricular. DVP com } \\
1,5 \text { anos. Fala e anda com dificul- } \\
\text { dade }\end{array}$ \\
\hline 2 & $\begin{array}{c}\text { Dilatação ventricular, calcificação } \\
\text { intracraniana }\end{array}$ & $2^{0}$ trimestre & Não & 34 & 2.400 & $\begin{array}{l}\text { Coriorretinite bilateral sem } \\
\text { seqüelas neurológicas }\end{array}$ \\
\hline 3 & $\begin{array}{c}\text { Dilatação ventricular, calcificação } \\
\text { hepática }\end{array}$ & Indeterminado & Irregular & 37 & 2.100 & $\begin{array}{l}\text { Microcefalia e alteração do de- } \\
\text { senvolvimento }\end{array}$ \\
\hline 4 & Dilatação ventricular & $1^{0}$ trimestre & Não & 39 & 2.835 & Neomorto (sepse precoce) \\
\hline 5 & Dilatação ventricular, CIUR & Indeterminado & Não & 35 & 1.100 & $\begin{array}{l}\text { Neomorto (toxoplasmose grave: } \\
\text { dilatação ventricular com cistos } \\
\text { cerebrais à necrópsia\} }\end{array}$ \\
\hline 8 & $\begin{array}{c}\text { Dilatação ventricular, calcificação } \\
\text { intracraniana, espessamento } \\
\text { placentário, hepato- } \\
\text { esplenomegalia, poliidrâmnio }\end{array}$ & $2^{\circ}$ trimestre & Irregular & 33 & 2.100 & Neomorto (toxoplasmose grave) \\
\hline
\end{tabular}

IG= idade gestacional; DVP = derivação ventrículo-peritoneal; CIUR = crescimento intra-uterino restrito. 
Entre os 12 fetos portadores de toxoplasmose congênita, oito apresentaram alterações à ultrasonografia (Tabela 2). A Tabela 3 correlaciona as alterações ultra-sonográficas com a evolução fetal.

As lesões cerebrais foram as alterações mais freqüentes. Dilatação ventricular bilateral, simétrica e de evolução progressiva foi encontrada em todos os fetos. Calcificações intracranianas foram observadas em cinco fetos. Em todos os casos as calcificações estavam associadas à dilatação ventricular e apresentavam aspecto grosseiro e localização periventricular.

Três fetos apresentaram espessamento placentário como evidência de placentite. Não foi observada alteração da ecogenicidade da placenta em nenhum caso. As lesões hepáticas encontradas à ultra-sonografia consistiram em calcificação hepática (1 caso) e hepatomegalia ( 2 casos). Outros sinais observados foram poliidrâmnio (2 casos), CIUR (1 caso), esplenomegalia (1 caso) e derrame pericárdico (1 caso).

Apesar de a maioria das pacientes não ter utilizado a medicação ou tê-la feita de forma irregular (Tabela 3), a avaliação ultra-sonográfica realizada 15 dias após o início da terapia revelou regressão da hepatomegalia, do derrame pericárdico e do espessamento placentário, além de normalização do líquido amniótico (casos 1 e 7). O mesmo não ocorreu com a dilatação ventricular, cujos controles ultra-sonográficos revelaram aumento progressivo da mesma em todos os casos.

A gestação evoluiu até o termo em quatro pacientes (casos 1, 3, 4,7 ) e quatro apresentaram parto pré-termo (casos 2, 5, 6, 8). Quatro recém-nascidos foram neomortos (casos 4, 5, 6, 8) por sepse neonatal precoce, toxoplasmose congênita grave e prematuridade extrema. Entre os quatro fetos restantes, o exame neonatal confirmou os achados ultra-sonográficos. À idade de um ano, três crianças apresentavam seqüelas: coriorretinite ( 2 casos) e atraso no desenvolvimento neuropsicomotor (2 casos). Apenas uma criança apresentou desenvolvimento normal.

Os quatro fetos que apresentavam ultrasonografia normal evoluíram até o termo apresentando exame neonatal e evolução clínica e neurológica normais à idade de um ano.

\section{Discussão}

A toxoplasmose é uma das infecções congênitas mais freqüentes ${ }^{3,10}$. No Brasil não existe programa nacional de rastreamento pré-natal para a toxoplasmose. No entanto, iniciativas lo- cais de determinadas regiões têm recomendado que os testes sorológicos para a toxoplasmose sejam realizados regularmente durante a gestação ${ }^{2,3}$.

A transmissão do parasita é rara no início da gestação, por outro lado, o acometimento fetal é mais grave nesse período ${ }^{1}$. As anomalias ultrasonográficas podem ser observadas em $30 \%$ dos fetos contaminados, principalmente no primeiro $(76 \%)$ e segundo trimestre $(22 \%)^{8}$. Nossos resultados confirmam essas observações, embora o número de casos estudados seja limitado: alterações ultra-sonográficas foram encontradas em $58 \%$ dos fetos contaminados no primeiro trimestre e em $22 \%$ dos fetos infectados no segundo trimestre da gestação.

Observou-se alta incidência de lesões cerebrais, na maioria dos casos associadas a outras alterações ultra-sonográficas. A dilatação ventricular foi o marcador ultra-sonográfico observado com maior freqüência. Ocorre por lesões de necrose na região do aqueduto de Sylvius ou formação de abscesso com gliose reacional e organização de exsudato rico em proteínas, provocando estenose ou obstrução, responsável pela dilatação que se inicia nos cornos occipitais, podendo acometer o terceiro ventrículo ${ }^{6,11}$. Normalmente simétrica, apresenta evolução rápida, com progressão significativa em alguns dias, tornando necessário o acompanhamento periódico desses fetos. Além disso, trata-se de alteração irreversivel, mesmo após o início do tratamento antiparasitário $^{12-14}$, e pode surgir algumas semanas após o diagnóstico da infecção fetal ou, muitas vezes, somente no período neonatal.

As calcificações intracranianas foram observadas com freqüência nos fetos infectados. Correspondem a focos de necrose observados como áreas de densidade aumentada à ultra-sonografia. Presentes nos hemisférios cerebrais, não são encontradas no cerebelo, tronco ou medula. Podem ser pouco calcificadas no período pré-natal e, dessa forma, dificeis de serem detectadas. Normalmente múltiplas, encontram-se associadas à dilatação ventricular com localização periventricular, e atuam de forma desfavorável na avaliação do prognóstico fetal. São bem demonstradas após o nascimento por ultra-sonografia transfontanela com sonda de alta freqüência $(7,5 \mathrm{MHz})$ ou tomografia computadorizada. A radiografia do crânio tem se mostrado método de baixa sensibilidade para sua detecção, principalmente em calcificações menores.

Alterações ultra-sonográficas relacionadas à infecção sistêmica pelo toxoplasma foram observadas com menor freqüência, o que estaria asso- 
ciado a tropismo do parasita pelo sistema nervoso central do feto. Alterações placentárias podem ser observadas em até $8 \%$ dos fetos contaminados e consistem em espessamento placentário, normalmente associado a ecogenicidade normal da placenta ${ }^{6}$. Trata-se de alteração transitória, indicativa de infecção placentária, e que apresenta boa resposta ao tratamento materno. Hepatomegalia e calcificação hepática são sinais de hepatite pelo T. gondii. Estão associadas a aumento na atividade da $\delta$-glutamiltransferase e de outras transaminases no sangue fetal. A esplenomegalia é identificada com menor freqüência, normalmente associada à hepatomegalia. Já o derrame pericárdico, sugestivo de cardiomiopatia pelo $T$. gondii, é observado em pequeno número de fetos associado a outros sinais sugestivos de infecção sistêmica pelo toxoplasma ${ }^{15}$. Essas alterações apresentam, como documentado neste trabalho, boa resposta à terapia anti-parasitária.

Embora o número de casos estudados neste trabalho seja limitado, nossos resultados demonstram a importância da ultra-sonografia para a avaliação do prognóstico e acompanhamento dos fetos apresentando toxoplasmose congênita, uma vez que pôde-se observar elevada incidência de alterações ultra-sonográficas nesses fetos, com grande número de óbitos neonatais e seqüelas de desenvolvimento.

O acompanhamento ultra-sonográfico prénatal desses fetos apresenta dois objetivos fundamentais. Primeiramente permite diferenciar os fetos portadores de infecção congênita assintomática, daqueles fetos apresentando alterações ultrasonográficas compativeis com a toxoplasmose congênita. Como pôde ser observado, os fetos assintomáticos (sem alterações ao ultra-som) parecem apresentar prognóstico favorável, pela ausência de seqüelas à idade de um ano. Entretanto, observou-se elevada incidência de óbito neonatal e seqüelas nos fetos apresentando alterações ultra-sonográficas compativeis com a toxoplasmose congênita. Nesses casos, o óbito parece estar relacionado a uma infecção em estágio avançado com comprometimento sistêmico grave e resposta inadequada ao tratamento. Já a incidência de seqüelas encontra-se associada à presença de lesões cerebrais, que, como pôde ser observado neste trabalho, podem levar a comprometimento grave do desenvolvimento neuropsicomotor dessas crianças.

Outro aspecto importante do acompanhamento ultra-sonográfico é a avaliação da eficácia do tratamento pré-natal nos fetos apresentando alterações ultra-sonográficas compativeis com infecção sistêmica como hepatomegalia, ascite e poliidrâmnio. Embora o número de fetos acompanhados neste estudo seja pequeno para se fazer uma avaliação, diversos autores têm demonstrado regressão dessas alterações ultra-sonográficas algumas semanas após o início da terapia pré-na$\operatorname{tal}^{4,5,12}$

Todos esses resultados demonstram que a toxoplasmose congênita pode se manifestar de forma grave durante a gestação, ressaltando a importância da ultra-sonografia no estabelecimento do prognóstico fetal e na monitorização do tratamento, permitindo a elaboração de conduta pósnatal adequada com o objetivo de diminuir a gravidade das seqüelas nessas crianças.

\section{ABSTRACT}

Objective: to describe ultrasonographic alterations in fetuses infected with Toxoplasma gondii, correlating them with neonatal prognosis.

Methods: between June 1997 and May 2003, 150 pregnant women with suspected toxiplasmosis were examined. Acute infection was confirmed in $72(48 \%)$ of these pregnant women and congenital toxoplasmosis was diagnosed in $12(16 \%)$ fetuses. Prenatal diagnosis was established by polymerase chain reaction in the amniotic fluid. All the patients received antiparasitic therapy. Ultrasound examination was performed every fortnight and all the infants were evaluated during their first year of life.

Results: ultrasonographic changes were observed in eight fetuses. All of them showed symmetric bilateral ventricular enlargement that was associated with periventricular calcifications in five cases. Other changes as hepatic calcification, hepatomegaly, polyhydramnium, and pericardial effusion were less frequent. Among these fetuses, four were stillborn and three showed sequelae (chorioretinitis and neuro-psychomotor retardation). The four fetuses that showed normal ultrasonography had a satisfactory development.

Conclusion: There was a high incidence of ultrasonographic changes in fetuses with congenital toxoplasmosis, mainly brain damage. Other changes as hepatomegaly and pericardial effusion were less frequent and were related to a systemic infection. The prognosis of these fetuses seems to be correlated with the presence of these lesions mainly because they had high mortality ratio and among the survivors the incidence of sequelae was high. The non-symptomatic fetuses evolved in a favorable way without developing sequelae. These results highlight the value of ultrasonographic examination of these fetuses in order to establish a prognosis and allow the elaboration of a suitable post-natal procedure.

KEYWORDS: Congenital toxoplasmosis, Ultrasonography, Prenatal diagnosis 


\section{Referências}

1. Wirden M, Botterel F, Romand S, Ithier G, Bourée P. Intérêt du dépistage en post-partum de la toxoplasmose congénitale après primo-infection maternelle en fin de grossesse. J Gynecol Obstet Biol Reprod (Paris) 1999; 28:566-7.

2. Spalding SM. Acompanhamento de gestantes com risco de transmissão de infecção congênita por Toxoplasma gondii Nicolle \& Manceaux, 1909 na região do alto Uruguai, RS, Brasil: diagnósticos e aspectos epidemiológicos [dissertação]. Rio de Janeiro: Fundação Oswaldo Cruz; 2000.

3. Vaz AJ, Guerra EM, Ferratto LCC, Toledo LAS, Azevedo Neto RS. Sorologia positiva para sifilis, toxoplasmose e doença de Chagas em gestantes de primeira consulta em centros de saúde da área metropolitana, Brasil. Rev Saúde Pública 1990; 24:373-9.

4. Friedman S, Ford-Jones LE, Toi A, Ryan G, Blaser S, Chitayat D. Congenital toxoplasmosis: prenatal diagnosis, treatment and postnatal outcome. Prenat Diagn 1999; 19:330-3.

5. Berrebi A, Bessières $\mathrm{MH}$, Cohen-Khalas $\mathrm{Y}$, et al. Diagnostic anténatal de la toxoplasmose. A propos de 176 cas. J Gynecol Obstet Biol Reprod (Paris) 1993; 22:261-8.

6. Abboud P, Harika G, Saniez D, et al. Signes échographiques de la fetopathie toxoplasmique. J Gynecol Obstet Biol Reprod (Paris) 1995; 24:733-8.

7. Crino JP. Ultrasound and fetal diagnosis of perinatal infection. Clin Obstet Gynecol 1999; 42:71-80.
8. Hohlfield P, MacAleese J, Capella-Pavlovski M, et al. Fetal toxoplasmosis: ultrasonographic signs. Ultrasound Obstet Gynecol 1991; 1:241-4.

9. Hadlock FP, Deter RL, Harrist RB, Park SK. Estimating fetal age: computer-assisted analysis of multiple fetal growth parameters. Radiology 1984; 152:497-501.

10.Vidigal PVT, Santos DVV, Castro FC, Couto JCF, Vitor RWA, Brasileiro Filho G. Prenatal toxoplasmosis diagnosis from amniotic fluid by PCR. Rev Soc Bras Med Trop 2002; 35:1-6.

11.Pedreira DA, Camargo ME, Leser PG. Toxoplasmosis: will the time ever come? Ultrasound Obstet Gynecol 2001; 17:459-63.

12. Cotty F, Carpentier MA, Descamps P, Perrotin F, Richard-Lenoble D. Toxoplamose congénitale avec hydrocéphalie diagnostiquée in utero: évolution sous traitement. Arch Pédiatr 1997; 4:247-50.

13.Virkola K, Lappalainen M, Valanne L, Koskiniemi M. Radiological signs in newborns exposed to primary toxoplasma infection in utero. Pediatr Radiol 1997; 27:133-8.

14. Couto JCF, Silva MVR, Leite JMB. Infecções perinatais. In: Melo $\mathrm{VH}$, editor. Ginecologia \& Obstetrícia: manual para concursos. Belo Horizonte: Medsi; 2003. p.817-28.

15.Rosenberg HS. Cardiovascular effects of congenital infections. Am J Cardiovasc Pathol 1987; 1:147-56.

Recebido em: 9/3/2004 Aceito com modificações em: 11/5/2004 